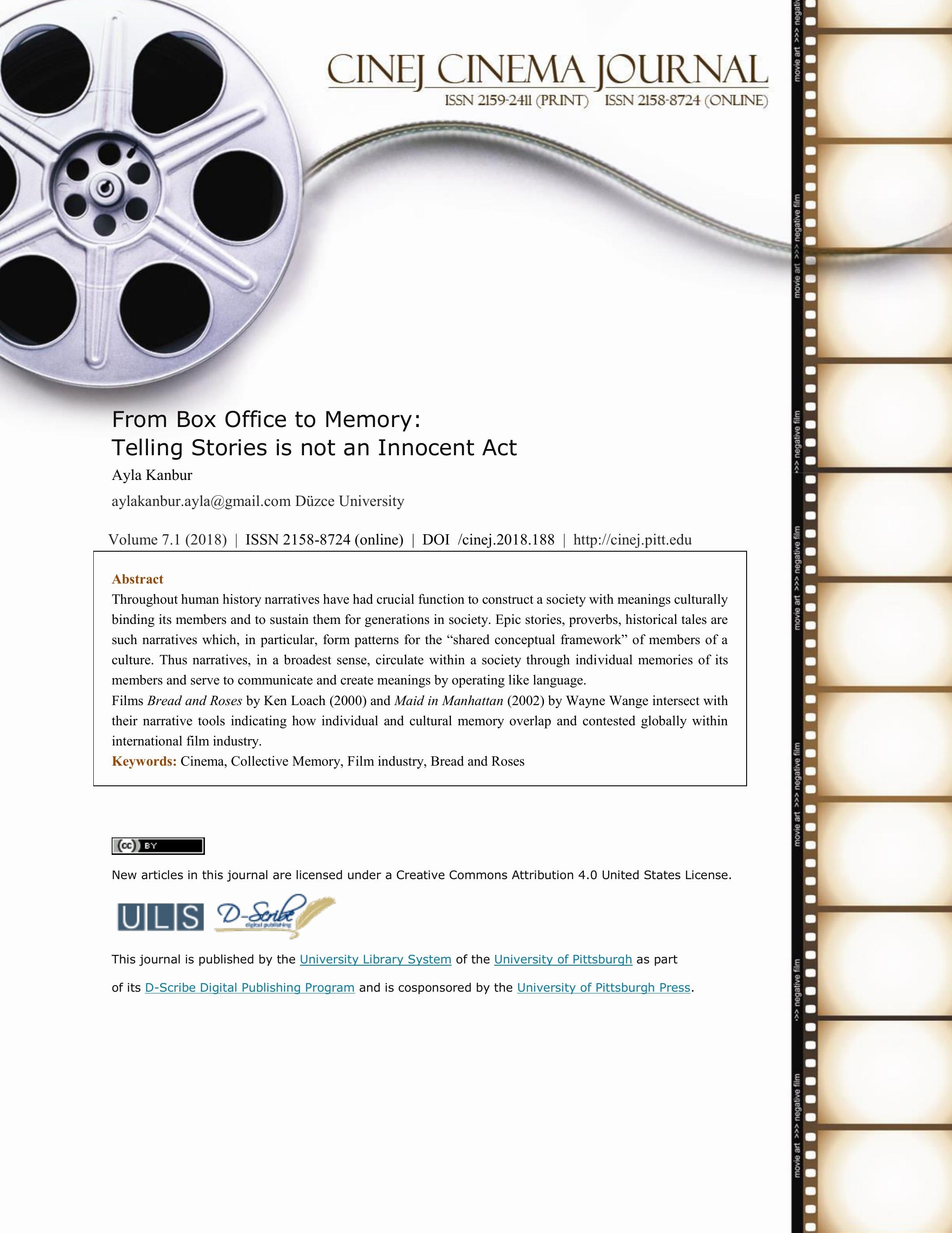




\section{From Box Office to Memory: Telling Stories is not an Innocent Act}

\section{Ayla Kanbur}

\section{Introduction}

Is collective memory able to record? To talk about collective memory seems to be impossible without referring or imagining an individual or a human being. Individuals are the bearer of actual events on their memory but collective memory is not their total, rather it circulates and distributes the meanings and values for the individuals to make sense of the events they live. Then, if they are not separable, what is their magic which cause us to feel as if the memory of our own only belongs to a personal life. What about watching a film?

Films cannot talk to themselves, they are made to speak. It means that "personal" belief and "values" of film makers and the audience communicate along with the films, which contribute to the maintenance of collective memory through their own ideology and the organized version of "personal memory". In other words, the process of film making and viewing will be articulated with the collective memory as, what Van Dijk calls, "personal cultural memory" (2004).

To begin with it is necessary to explain the writer's personal mnemonic moment which inspired this paper. As an "actually lived context", watching Maid in Manhattan (2002) reminded Bread and Roses (2000) unintentionally after 10 years gap in between period. Then, related conversation on Bread and Roses by critics was followed: "being ordinary, too much politics, slogans etc.", and to which the reflection of the writer of this paper was that "sometimes we needed to be reminded of the reality in a simple way by film making". This sequence of the mind in the actual moment cannot be relived but we can only try to capture or rationalize it again. Why did one film trigger the mind to remember other one? 
The answer would be "lived experience", stored images and visions that somehow were registered in personal memory. Those moments, which may be described as "flash bulb" remembering, must be familiar to everyone. It is namely, when something triggers an individual's memory without any conscious effort to remember something. John Grooger $(1997,327)$ in the glossary of his book describes it “individual's recollections of widely experienced events and circumstances in which these were encoded." Flush pulp memory may correspond with Marcel Proust conception of "involuntary memory" which Walter Benjamin (1993, 101-116) praised in his famous "Image of Proust" passage. In the same way, in his exploration the philosophical tradition on mind and remembering, Paul Ricouer clears the distinction between the quest for a memoir and remember it unintentionally $(2012,31)$.

In the case of momentarily or entirely remembering, the implication of individual brain is at work. On the other hand, when we utter collective memory, there is no reference to any tangible body. If there is no organ for the notion of collective memory, what do we talk about? The answers vary depending on the perspectives from which any social discipline would focus.

While collective memory has long been an interest for scholars ranging from cognitive sciences to social politics, the medical developments in brain has increased the attention to individuals since last few decades. In other words, new researches of neurosciences enlighten physical dimensions of human brain, thus, collective memory in social studies has gain more substantial connections between human psyche and social being. Social science researchers have then driven their attention to grasp "the full complexity of the engagement of the mind in culture and history", that is "not only created by people but that creates persons". (Bloch 1996, gtd. in Brockmeier 2002, 6-7) 
Volatile nature of daily life experience of human being might be one of the difficulties to speak precisely about societal dimension of individual memory. As human brain is instantly active in time, it requires to be investigated for not only how it works in an individual level but also how that particular individual's brain responses to various social, cultural and environmental stimuli. On that account, Keithley turns our attention to "confusions, silence and absence in memory" and asserts that "remembering is not just an articulation of individual psychologies, but a performance rooted is lived contexts" $(2009,58)$.

This active dimension of individual memory also implies its unreliability, especially in the experimental work of Elizabeth Loftus. (2002). She proves that how 'eye-witnesses' or people who try to remember a lived experience can be manipulated by cultural products, such as advertising. Her researches have resulted in claiming that people re-construct their actual experience when they remember the past experience through a mediation. Another research by Loftus and Palmer has shown that how a recollection of a videotaped car accident can be manipulated by chosen words. "The authors showed that the recalled speed depended heavily on the power of the verb used in communicating" (1974 qtd. in James V. Wertsch, Henry L. Roediger 2008, 322)

In the above context, the actual experience recorded by our memory and its deviation in the process of remembering may open up one of the possibilities to investigate how cinema can, in associations with the repetitions of chosen meanings, transform personal memory to a supposedly actual experience. Accordingly, this paper will suggest that film industry plays a crucial role on the distribution of social and cultural values -serving to maintain collective memory- in the form of narrative. In this respect, narrative in a simple sense of story-telling one of the strong ways which articulates personal memory with collective memory, vice versa, in a given culture. Thus, it will be claimed that film industry in a capitalist society inevitably would 
reflect the contested nature of collective memory for the maintenance of certain values via repetitive themes in narrative in personal memories.

\section{The Sphere of Collective and Personal Memory: Functions of Culture in General}

Cinema, with its visual and narrative structure, directly communicates with audience, society and distribute/reproduce meanings to cultural web more than literature would achieve. It is mainly because of the verisimilitude nature of the visual material recorded. This property of camera increased the attention to memory, since their invention in late $19^{\text {th }}$, early $20^{\text {th }}$, as "the search for the time lost arises in throes of the sociocultural earthquake called modernity." (Brockmeier 2002, 20) Considering the way the past is established by visual as undeniable evidences, the appetite for recording daily life, people, social events, making archives, commemorations indicate contestant nature of collective memory.

Counting on the individual recollection and experience gained with films in a certain culture can be taken as an arena of this hegemonic struggle on collective memory. Even the emergence of the idea for this paper points how individuals' brain actively works and articulates with the meanings and the past. While watching a film to remember another one or associate it with outside of film texts is the activity of brain and our perceptual storage. What would the reason be behind this remembrance? Or, how and why are audiences' mind are kept updated with certain stories and how others are left to the dark side of forgetting. During watching a film our intellect works and our attention is floated but we make sense with the clues of scenes and dialogs and their systematic combination. We are, as the agents who carry, activate and participate in the circulation of meanings, in the endless associations of our memory. Therefore, which meanings and which films strongly occupy our memory and reinforce our values and beliefs is a subject worth of 
exploration of memory studies, especially in the junction of narrative, individual and collective memory. Recent studies on memory in several disciplines illustrates how complex the processes through which our memory works. Especially in the age of the media, the research area has offered a wide range of conceptualizations and the point on which was mostly agreed has been the bond of personal memory and culture, society and environment. Both the studies on personal and collective memory have concurrently expanded their corpus with the research outcomes and theories in each focus area.

The fact that thinking over the past is always at present moment creates an ever changing perspective towards the past, so is the imagination of future self, even in its collective form. ${ }^{1}$ In the sense of past and constructing an identity for a specific social group the history seems strongest written evidence. However, W. Wertsch and H. Roediger situate collective memory in contrast to history. Even though commemorations, monuments, architecture, education material overlap with the sense of historical past, they are at the serve for collective memory preserving sense of cultural identity. Collective memory or "collective remembering", "involves identity project, based on heroism, a golden age etc", and aims to "preserve established narratives, relies on implicit theories, schemas and scripts that simplify the past and ignore substantiated findings that do not fit the narrative." (2008, 321) Then, "collective remembering" can be regarded as a space in which "social and political contestation that is part of many accounts of the past." (Wertsch and Roediger 2008, 319) Temporality of memory also creates a tension between groups to maintain their identity against others. Whereas contestation gives it the conservativeness to preserve the glue, historical changes force it to reconsider or adjust to the demands of the present. Either in terms of contestation or investigation of its characteristics, almost all studies on collective memory

\footnotetext{
${ }^{1}$ On the history power and the role of historicist see Walter Benjamin (2003, s.391), Paralipomena to "On the Concept of History", Selected Writings. Volume 4.
} 
(sometimes social, public, cultural memory) cannot elude the individual who embodies it. However, some of them prioritize culture and society. Jan Assmann $(1997,40)$ states that there cannot be a memory of society but societies establish the memory of their members; the subjects of memory and remembering are always individuals but they are always bound up in a framework which forms their remembrance.

The framework of individual memory constructed by culture and its products has also been the focus of some scholars. Jose Van Dijck (2004, 267-268) explores the various cultural sources and suggests the notion "personal cultural memory" in regard to the fundamental bond between individual and collective. He places our individual collections of recorded cultural content, such as photographing, writing dairies, as "mediated memories" which play an important part for individual and collective identity as a means for remembering and creating continuity between self and others. Collective memory means that people must have the feeling that they were somehow part of the communal past, that there was some connection between what happened in general and how they are involved as individuals." (267-268) Roediger and Wertsch (2008, 18-326) summarize the varied approaches to the connection between individual and collective memory as "socially situated individuals are the agents of remembering." In other words, the way "their (individuals) use of cultural tools for remembering reflect the socio-cultural settings" (Wertsch, 2002, qtd. in Wertsch and Roediger, 322). Roediger and Wertsch's emphasis is on which the tools are distributed, and rely extensively on semiotic means that are provided by cultural, historical and institutional contexts. In the same vain, Bruner states that what makes collective remembering collective is that members of a group share the same cultural tool kit.” $(2008,323)$

The statement of Van Dijck $(2004,268)$ individual agents as active producers and collectors of mediated memories is akin to socially situated individual of Wertsch and Roediger. 
While individuals contribute to collective memory using cultural tools, such as language, writings or filming, those in turn create a framework and network to which memory remembers. Rather than recalling the past as it is experienced, personal memory is 'the intersection of collective influences' from familial conventions to cultural norms. . In this context, Keithtley turns our attention to the representational status of memory. "To be communicable and meaningful memories have to be reconstructed as representations. ..... Private memories can be represented through spoken narrative or family album. In public, collective memories can be encoded ... from feature films to political speeches. Both private and collective remembering draw on contribute to cultural representations and symbolic repositories." (Keightley 2009, 58) The term "mediated memories" refers to access to such tools and constructing a common cultural practices those of which have already gained significance by collective cultural past. Mediated memories or "distributed remembering" through culturally representational forms potentially bring the struggle either against domination between different groups, or tension between the individual memory and collective memory, in order to control or overrun the present, so the future. "In the acts of representation and communication, multiple social and cultural codes of remembering are performed and reconciled, resisted or rejected in a constant process of locating and relocating the subject in time and space and meaning. ....Conflicting and competing memories are constantly in the process of construction in the ongoing exchange between collective and personal accounts. In this constantly shifting context, both individual agency and hegemonic power are at play." Likewise, Wertcsh and Roediger $(2008,322)$ has indicated, distributed remembering is the question of how different cultural tools might give rise to the different forms of memories. Culture in a broadest sense involves almost every performance of subjects and equipment, and unless it is regulated or put in order, we wouldn't be able to share, extend over time or preserve it. For this 
purpose, narrative is not only one of the organizational forms of events but also is the means which mediates between individual memory and collective memory.

\section{Narrative as a Cultural Form of Autobiographical Memory and Cinema}

The concept of narrative, historical, parental, national, cultural or literary seems to be one of the main concepts mostly adopted in both research directions, particularly at the intersection of personal and collective memory. How a life story -autobiography- is constructed calls the researchers to consider the narrative form as one of the constructive categories of autobiographical memory, at cultural as well as at individual level. The most common implications are on communicative function of narratives as a glue binding individuals to society and culture particularly in terms of values and beliefs. (Nelson 2003,127)

In her quite comprehensive essay Self and Social Function: Individual Autobiographical Memory and Collective Narrative Katherine Nelson $(2003,126)$ points the importance of episodic memory which functions in establishing a link between individual and culture through narrative. Drawing on Tulving's ([1983]) distinction between episodic memory and declarative memory, Nelson (2003) puts episodic memory as "temporally sequenced events or activities which may have evolved as functional for certain kind of knowledge, i.e. how to build a nest? ...Episodic memory in particular characterized by autonoesis, re-experience of the past, as distinguished from semantic memory, noesis, that is, factual memory with no accompanying sense of selfexperience"(126).

Not only does language serve as a symbolic means for passing the experience individually lived to other members of society, but also its organization as narrative expands the personal knowledge, experience and thoughts to socially shared memories. -In this respect, the connection 
between cinema and experience is worth re-assessment.- The notion of autobiography implies a narrative structure in terms of making sense of one's own self to exist as coherent individual in cultural exchange. In other words, temporally lived and fragmented experience, any connection with objects, images or places etc. external to individual only make sense, or can be translated within the same map of a given culture. Nelson's work (2003) also indicates that to use narrative structure is something we are forced to learn from birth especially in western culture (128). Her examples demonstrate that the individualism rising with the social changes which, in turn, constantly restructure the narratives. Watts ([2001/1957]) designates the novel as "wholly written literary genre" (Nelson 2003). The period of industrialism is defined as the historical shift from mythic and common narratives of culture to the individualistic perspectives. In the light of this evolution of narratives to the autobiographies, Nelson points that "these written forms of a person's own life (ongoing or retrospective and reflective) transformed everyday personal episodic memory into retelling of a life story that at least sometimes meant to be shared" (28).

In awareness of the discussion above we may infer that through all historical cycles of culture people learn how to transfer some knowledge or life patterns into their personal life in dominantly with narrative form beside other cultural tools. In other words, narrative as a cultural “invention" differs from "experiential time” (129). Nelson (2003) takes her point further: Making personal narrative out of episodic store of individual memory is one of the forms which have been adopted during early childhood in a specific culture and period. This particular cultural narrative form and the selection for its content from personal experience for a coherent self may occur differently in other cultural landscapes. Counting on researches, she claims that the different perceptions about past in Asian societies from western "in the absence of models who provides in formulating narratives about the personal life and societal values that give such narrative meaning 
individuals do not compose life stories in the same that we expect people in western countries to do" (131).

In the context of narrative as a prevailing form of personal memory which is the link to the shared collectivity, , we may position cinema as a stronger link at a time when it is born, ready to evolve to narrative form and captivate large popular audience. Especially, for the audience of western culture would not be hard to link two successive shots in a rational way.

Even it would seem to be questionable, it would be claimed that early steps of cinema towards narrative had been culturally bond to the collective memory in its contested nature. While the transition to narrative cinema depended on the early economic and cultural conditions, we would all agree on that early films were consisted of single shot or more without continuity editing. ${ }^{2}$ Analogically we can take it as episodic memory as temporally sequenced events, like in Lumiere Brothers, not yet transformed to wholly narrative form which was culturally ready to be understood. But when at least two different shots were put next to each other about the same event, even it is not causal relation, it must make sense for the audience, or else audience was going to connect these two shots with the sense which gained from daily life experience and familiarity with narrative form. For example, two people run in the same place with different shots, we would tell one is escaping, other tries to catch them, or without any relation we would say two different people are running on the same place. In each case, audience would try to make sense the scenes. In this sense, to remember Kuleshov's experiment would be adequate. In short, we relate to any narrative, -oral, literary or cinematic- by applying it to our own conception and experience of the world, which is a certain cultural logic, and in turn we project our personal perspective to events

\footnotetext{
${ }^{2}$ Elsaesser, Thomas and Barker, Adam, (Eds.) (2008), Early Cinema: Space, Frame, Narrative, British Film Institute
} 
which establish a commonality. With the independent shots successively follow each other, a coherent meaning through inference were not unfamiliar to the audience, in both sense episodic memory and its organization for coherent self-subject.

By now, it seems apparent that narrative plays a pivotal role in collective memory to construct, adjust and maintain with loaded particular meanings. It also provides the basis for "distinguishing it from different cultural tools" as in Assmann's distinction between" narrative and non-narrative forms (landscapes, food etc.) of cultural memory" (Wertsch and Roediger 2008, 323). Additionally, narratives, which construct meaning, serve for the coherent national as well as personal identity formation as in the case of autobiographical memory. ${ }^{3}$ They represent the past by binding events, characters and motives under a rational way. These are the forms in which individuals share and access what makes collective memory collective, and what makes sense of their life and experience. Moreover, we should not fail to recall that they have the temporal dimension like in parallel with memory. Assmann indicates that "to which they are shaped in accordance with, and through the lens of, present, the history turns in to myth as soon as it is remembered, narrated, and used, that is, woven into the fabric of present" (qtd.in Wertsch and Roediger 2008, 321).

At the individual level, cinema as a form of narrative provides the basis to access and repeat collective myths beliefs and values, which circulate in a particular culture of group of people. Besides the debates on narrative as something that we learn or as something we inherit which enables us to use our memory, we always re-construct even the same event from prism of our present situation. In addition, remembering the past always impairs with something else, such as a word, a place, an image, through which we relate the specific event. The results from the researches

\footnotetext{
${ }^{3}$ See more and compiled researches on the special issue of Memory, Volume 11 Number 2, 2003 Psychology Press:Taylor and Francis
} 
by various disciplines reach at a basic distinction "between forms of memory mediated and those that are not". The distinctions between imagistic and narrative, implicit and explicit or unaware and aware uses of memory indicate that the former ones (imagistic, implicit, unaware) gains meaning with their translation into narrative, to the latter (narrative, explicit, aware) by language. (Wertsch and Roediger 2008, 323) In other words, they are the transitions of our experience into conscious building and pattern of a logic.

All those studies and conceptions on memory may shed light on new perspectives to consider cinema, as a cultural form which distributes memories, re-shape or strengthen our cultural or personal cultural narratives. Whereas the repetition of some cultural themes is an essential act for collective memory to remember, not to mention some themes of culture may cause to forget; as in the tradition passing from one generation to another through repetition. In this sense forgetting has a fundamental function in our culture as in what Andreas Huyssen emphasizes the politics of forgetting in his studies. ${ }^{4}$ Both films which are analyzed below will specify contested, distorting, and transforming nature of collective remembering through cultural forms and their contents chosen from social and cultural repertoire

\section{Whose Collective Memory is it?}

\section{Bread and Roses or a president in the White House}

If 'socially situated people' are the agents of remembering, they are also the agents of collective forgetting. By the selection from their cultural memory, filmmakers are included in this

\footnotetext{
${ }^{4}$ See expecially Huyssenn, Andreas. "Present Pasts, Urban Palimpsests of the Policitics of Memory" (2003) Stanford University Press
} 
chain. With their own perspective to their own reality and experience of life they offer a life pattern through visually told narrative..$^{5}$

On the other side of this communication, film viewing take place, that is, activation of audience's experience through cognitive process. Audience, who are mentally active in film viewing would register emotional and/or rational moments in mind as in imagistic or episodic memory. How we register a moment to our personal memory while watching a film? One of the answers would be to empathize with characters. (Neil, 175-178) Empathetic responses also play an educative role for our personal experience. The imaginative activity is involved through the assimilation of the character's situation, in which we must have conception, or understanding "internally" how the protagonist sees the situation. It is not only technically "point of view shot", it is also whole construction of a narrative perspective from which character(s) go through. (1996, 191)

Cinema as a medium circulating stories, as one of the cultural forms appealing to masses, its industrial dimension is worth consideration in the context of collective memory. Whereas certain social norms, values and beliefs would be emphasized in these stories and patterns of narratives, others would be left to be forgotten or recounted from different perspective in regard to needs of present. In this sense, some values will gain significance by individuals experienced in film viewing with repetitive themes and perspectives in industry. If the society culturally informed by narrative recounts, then each single film will relate with each other's, nurturing the collective memory in a certain way.

\footnotetext{
${ }^{5}$ It would also be worth having a deeper look at the relationship between the directors' own life and their films in this sense but it is beyond the scope of this work An excellent work on this matter, see Sefcovic, Enid. (2002): Cultural memory and the cultural legacy of individualism and community in two cultural films about labor unions, Critical Studies in Media Communication, 19,3, 329-351
} 
The intertextuality of film narratives as in literature, ${ }^{6}$ not only braces narrative form but also distributes globally its themes, creating similar perceptions of and perspectives to our reality. To express this point, we should remember the beginning of this paper. In the actual viewing moment two films reminded one another by their filmic material, however they were constructed to address different social values. In other words, they relied on audience's re-collection of past, their different life experience by re-building the events according to the present.

What do the two films, Bread and Roses (2000) by Ken Loach and Maid in Manhattan (2000) by Wayne Wang, offer to the audience by arriving to a meaning about our experience of life via its subject matter and narrative construction? Because of the box office they made, asking this question may be worth of comparing the two films. They were released two years after one another, Bread and Roses (2000) by Ken Loach and Maid in Manhattan (2002) by Wayne Wang. The former's box office was $\$ 525,738$ and the latter's was $\$ 93,815,117$ in the US (www.imdb.com). They may not be acknowledged as master pieces as they have neither outstanding content nor plot line. Both the way they tell their story in a very basic narrative structure which all cinemagoers already have familiarity and would easily make sense the films.

Maid in Manhattan (2000) is about a love story between a Latino maid who is a single mother working in a luxury hotel and a Senate candidate to the Republican Party. A coincidence brings them together, whereas the man is unaware of her social position. This misinformation is resolved in the end, and they get married. Their marriage and the following years of the couple are covered by the media as a fairy tale. The film's pattern is not only based on Cinderella, but also depicts some specific aspects of fairy tale, like the step mother as her own mother, the wealthy

\footnotetext{
${ }^{6}$ For a study between literature and memory Erll, Astrid and Ann Rigney, Literature and Production of Cultural Memory: Introduction”, European Journal of English Studies, 10:2
} 
female rivals as her sisters, and her colleagues in the film as guardian angels. The coverage of media at the end of the film also convinces us fairy tales can be true.

Bread and Roses (2000) is about union struggle against a company that provides janitors to a tower in which several influential companies have their offices. A Mexican girl who flees to America finds a job in a janitor company in which her sister works. After a unionist's action to convince them to be the members of the union, she realizes the pressure on the workers of the foreman and the exploitation the workers face. She works with unionist to organize her colleagues for their rights and janitors gain their rights after a series of struggles. However, the girl who has migrated to the US at the beginning of the film, is deported to her country because of violation the US rules. Her all hopes are interrupted but she leaves the country with victory and feel proud of herself doing the right thing.

Both films can be compared and contrasted with each other by their approaches the circumstances of single woman's life from different points of view. By employing similar material their narrative is organized to serve to collective memory repertoire. Both films employ Latinos as main characters. Maid in Manhattan does not nominate race, which is also important in terms of contradicting nature of distributed collective memory, nor is the class struggle for the heroin in the film applicable. Another contrast is the colleagues of the main characters' and their relationships with each other as a portrait of a community in which the habitants share the same social and harsh economic conditions; either a servant or a janitor who is always secondary or better to say, almost invisible in society which is projected in Bread and Roses.

Maid in Manhattan reminds the mythic belief about love and individual salvation and encapsulates not only the people in the US but also globally distribute the values of capitalist society. The ideology of individualism, which is one of driving forces of capitalism, is reinforced by the film's narrative. The candidate of senate is a republican who confronts to the democrat son 
of protagonist woman. Republican candidate tolerates the son's arguments and they meet in the middle of being human. The audience is also convinced in the end of the film with media coverage in diegesis, -there is always a way to live better if you do not complain and work hard and if you are contented with your position. - It may be coincidence that the release year of the film is 2002 , after the attack to the twin towers in 2001. Nevertheless, the candidate of senate embodies the model of the American Presidents' image which has also been imposed by real events after September 11, such as America and freedom, and romantic and sensible President who does not discriminate people in terms of class or race.

Bread and Roses, on the other hand, may be taken as different cultural memories and remembering against Cinderella-like myths. Even it includes victory over exploitation with a hopeful future deriving from the past experience, it takes place in the perspective of a world of which images of struggle or class society is already defeated by surrounding counter arguments and narratives. Although Ken Loach always sets the class society in his films, Bread and Roses was released when anti-capitalist movements globally were in the peak again after years of 60's.

Above all, the name of the film refers to a history of labor struggle which the film's circulation re-vitalizes the memories of already collectively forgotten labor movement in 1912 in US. -Whereas Maid in Manhattan relies on Cinderella structure which re-confirms historical collective memory. Bread and Roses also reminds that for a victory for human rights, the communal struggle with solidarity is inevitable. So, rather than individual luck, to identify your own position among the people having the same social and economic situation like you is necessary to gain power. In addition, it re-turns our attention to the characteristics of the class society and struggle against it encompassing different races, gender and age; elderly females, a migrant from socialist block, black Americans and not specifically no-name Latinos but South 
American people from different nations are all in spot. People from South America is also another poke which activates memory and makes us recall the long social and political suffering of South America with its political chaos against US politics.

We do not need to mention Hollywood, finance and politics network, films as cultural products of the acts of film makers' as the bridge between individual and collective memory. Telling stories are not only simple creative choices; considering the act of remembering occurs in a framework, or cultural tools in another sense, with which the memory of subjects are organized, to predict the forgetting would not be complicated -beside the dynamics of power and hegemonic contestation at work. In words of Jan Assmann:

"if a person -and a society - may re-constitutes the past within the framework or context which s/he relates, everything outside of that frame work will be left to be forgotten. As individual memory grows in a person through the contribution to communication process, memory maintains its vitality in that process. If the exchange between memory and communication suspends or if the framework of the reality of which the exchange takes place changes or disappear, forgetting arises." $(1997,40)$

There can be more to state how films, particularly these two films, bring into play the collective cultural memory. But what seems certain in our context is that their narratives are derived from the collective past, distributed at present and projected experience for the future imagination. Collective memory as a rather intangible entity can be concretized on the base of cultural tools of mediation which circulates certain forms and meanings for activating individual memory. Narrative form as the tool overlaps both memory. Cinematic narrative, in particular, interrelates with our experience creating new episodes on our memory and makes changes in opinions, themes, ideas which are worth of remembering. Hollywood as a prevailing film industry holds the power to distribute these meanings globally. In this context, this paper tried to illustrate the function of cinema in which collective and individual memory meet by mode of production 
and distribution of film industry. In conclusion, it may be claimed that cinema can offer the link between collective memory and a specific economic system.

\section{BIBLIOGRAPHY}

Assman, Jan. Kültürel Bellek (Trans. Ayşe Tekin), C.H Beck: Munchen, Istanbul: Ayrıntı, 1997

Barnier, Amanda, J.and Sutton, John. "From individual to collective memory: Theoretical and empirical perspectives”. Memory. 16.3 (2008): 177-182

Benjamin, Walter. "On the Concept of History". Selected Writing Volume 4. Howard Eiland and Michael W. Jeannings (ed.), trans. Edmunt Jephcott and Others, The Belknap Press of Harward University Press, 2003.

Huyssen, Andreas. Present Pasts: Urban Palimpsests and the Politics of Amnesia. Ed. Mieke Bal and Hent de Vries. Stanford: Stanford University Press, 2003.

Keightley, Emily. "Remembering research: memory and methodology in social science." International Journal of Social Methodology 13.1 (2009): 55-70

Neill, Alex. "Empathy and (Film) Fiction" David Bordwell and Noel Carroll (Eds.). Post Theory: Reconstructing Film Studies. University of Wisconson Press, (1996): 175-193

Nelson, Katherine. "Self and Social Function: Individual autobiographical memory and collective narrative”. Memory. Psychology Press: Taylor and Francis 11. 2 (2003):125-136

Sefcovic, Enid. "Cultural memory and the cultural legacy of individualism and community in two cultural films about labor unions". Critical Studies Studies in Media Communication. Routledge 19.3 (2002): 329-351

Wertsch, James V. and Henry III L. Roediger. "Collective memory: Conceptual foundations and theoretical approaches". Memory 16.3 (2008): 318-326.

Van Dijck, Jose. "Mediated Memories: personal cultural memory as object of cultural analysis". Continuum 18. 2 (2004): 261-277 